\title{
Seroepidemiology of rubella in Saudi Arabia: adapted vaccination policy
}

\author{
M A ABDULLAH, ${ }^{1}$ GHAZI JAMJOOM ${ }^{2} \mathrm{Z}^{\text {A KARRAR, }}{ }^{1}$ AMAL BADRELDINE, \\ NUHAD AL JISHI, ${ }^{1}$ AND S A TAHA ${ }^{1}$ \\ From the Department of Paediatrics ${ }^{1}$ and Department of Microbiology, ${ }^{2}$ College of Medicine, Riyadh, Saudi \\ Arabia
}

SUMMARY Rubella haemagglutination antibodies were tested for in sera of 1793 unvaccinated subjects with age ranging from birth to 40 years. This was to assess the immune status of the population and to see the feasibility of introduction and the proper age for rubella vaccination in a Saudi community. Those with titres of $\geqslant 1: 8$ were considered as seropositive. The lowest level of antibodies was seen among the 10-18 month age group. All children aged 2-5 years were seropositive as were $75 \%$ of the elementary school girls. Only $90-95 \%$ of the women ofo childbearing age were seropositive, however, leaving an immune gap of 5-10\%. Unnecessary mass vaccination of young children is discouraged. Rubella vaccine should be given to all final: elementary school girls and all women of childbearing age after scréening, whenever possible. Special catchment zones are suggested for the latter group. Further nationwide seroepidemiological surveys are recommended for the other parts of the Saudi Kingdom.

The major clinical sequelae of rubella, which occurs after rubella infection in early pregnancy, are fetal wastage and the congenital rubella syndrome. ${ }^{12}$ In Saudi Arabia cases of congenital rubella syndrome are not infrequently observed. In 1981, for instance, four cases were admitted to Riyadh Maternity and Children's Hospital. ${ }^{3}$ The actual figure could be much higher as most cases are not immediately apparent, missed if mild, or present elsewhere.

As the congenital rubella syndrome is untreatable, prevention is universally regarded as imperative. A live attenuated vaccine has been available for many years and has been introduced into many countries who adopted different vaccination policies. ${ }^{45}$ Nevertheless, it is necessary to know the rubella susceptibility in a population in order to determine the feasibility of rubella vaccination as a national policy. Apart from one study by Basalamah ${ }^{6}$ from western Saudi Arabia there is no other published information. In particular, there are no studies on the immune status of the younger age groups who are now being chosen as a vaccination target in some countries such as the United States. The purpose of this study is to provide these data in order to determine the feasibility of and the proper age for vaccination.

\section{Material and methods}

The present study included 1793 individuals. Their age ranged from birth to 40 years. They were subdivided into four main groups, whose numbers and distribution are shown in table 1.

Preschool children drawn randomly from our hospital nursery and children attending the paediatric outpatient and well baby clinics: 156 (59 boys and 97 girls) out of 1200 subjects were randomly selected. None of them had been vaccinated against rubella.

Schoolgirls-A multistage stratified random sampling technique was used to draw this sample. One of the five Riyadh school health units was allocated for the study. It consisted of schools distributed in different parts of the city which differ in their degree of affluence. The total number of girls in

Table 1 Total number and distribution of population

\begin{tabular}{lccc}
\hline Group & No & Females & Males \\
\hline Preschool children & 156 & 97 & 59 \\
Schoolgirls and university students & 962 & 962 & - \\
Antenatal group & 675 & 675 & - \\
Totals & 1793 & 1734 & 59 \\
\hline
\end{tabular}


the health units was 10200 , of whom 930 were included in this study.

University female students were drawn from King Saud University female students. Only 32 students volunteered. Full data including age, nationality, and history of rubella or rubella vaccination were obtained by a female member of our team directly interviwewing the students or their parents (in the younger age groups). Blood samples were then collected after obtaining written consent.

Antenatal group-Sera were obtained from women (aged 15-40) attending King Abdul Aziz University Hospital antenatal clinics where blood is drawn routinely for rubella screening. Information on age of patient, nationality, and rubella vaccination status were obtained from the patients' records The total number studied in this group was 675 out of 6800 .

\section{COLLECTION OF SAMPLES}

Three to five millilitres of blood were collected and allowed to clot at room temperature. Sera were separated by centrifugation and stored at $-20^{\circ} \mathrm{C}$ until tested for rubella antibodies.

\section{Test for rubella antibodies}

Antibodies for rubella were measured by the technique of haemagglutination-inhibition using microtitre equipment. The technique is basically as described by the Center of Disease Control, Atlanta, Georgia, ${ }^{7}$ except that sera were treated with the kaolin micromethod as described by Inouy. ${ }^{8}$ Pigeon blood, hepes saline albumin gelatine (HSAG), and dextrose gelatin vinoral DGV buffers (from Flow Laboratories, Irvine, Scotland) were used. All sera with titre of $\geqslant 1: 8$ were considered as positive- that is, immune. Those with titres of $<1: 8$ were considered as negative-that is, susceptible.

\section{Results}

Table 2 shows the antibody status among the preschool children. All the 0-9 month group were seropositive. The percentage of children with relatively high antibodies $(\geqslant: 8)$ was lower among the

Table 2 Immunity status to rubella among preschool children

\begin{tabular}{|c|c|c|c|c|c|}
\hline \multirow[b]{2}{*}{$\begin{array}{l}\text { Age group } \\
\text { (months) }\end{array}$} & \multicolumn{2}{|c|}{ Seronegative } & \multicolumn{2}{|c|}{ Seropositive } & \multirow[b]{2}{*}{ Total } \\
\hline & $\begin{array}{l}N o(\%) \\
<1: 8\end{array}$ & $1: 8$ & $\begin{array}{l}\text { No }(\%) \\
<1: 8\end{array}$ & $\geqslant 1: 8$ & \\
\hline $\begin{array}{c}0-3 \\
4-9 \\
10-18 \\
19-24 \\
25-60\end{array}$ & $\begin{array}{c}0(0 \cdot 0) \\
0(0 \cdot 0) \\
15(65 \cdot 2) \\
4(15 \cdot 4) \\
0(0 \cdot 0)\end{array}$ & $\begin{array}{r}13(30 \cdot 2) \\
18(60 \cdot 0) \\
8(34 \cdot 8) \\
14(53 \cdot 8) \\
13(38 \cdot 2)\end{array}$ & $\begin{array}{c}30(69 \cdot 8) \\
12(40 \cdot 0) \\
0(0 \cdot 0) \\
8(30 \cdot 8) \\
21(61 \cdot 8)\end{array}$ & $\begin{array}{c}43(100 \cdot 0) \\
30(100 \cdot 0) \\
8(34 \cdot 8) \\
22(84 \cdot 6) \\
34(100 \cdot 0)\end{array}$ & $\begin{array}{l}43 \\
30 \\
23 \\
26 \\
34\end{array}$ \\
\hline
\end{tabular}

4-9 months group than the 0-3 months age group, indicating gradual loss of transplacental antibodies. The lowest level of antibodies was found among the 10-18 months group. Thereafter, the percentage of seropositive children increased progressively, and almost $100 \%$ of the $24-60$ months age group were seroimmune.

Table 3 shows the immune status among schoolgirls and university students: $24.4 \%$ of the elementary schoolgirls were susceptible. This figure, however, dropped to $8.5 \%, 11 \%$, and $6.3 \%$ among the junior secondary, high secondary, and university girls respectively. In this group 115 students gave a negative history of rubella or rubella vaccination yet $104(90 \cdot 4 \%)$ were found to be seropositive. Nineteen gave a positive history of rubella and were all seropositive. There was no significant difference between Saudi and non-Saudi students who formed $16 \%$ of the study group.

Table 4 shows the immune status among the antenatal group: $5.6 \%$ were considered susceptible to rubella and $591(87.6 \%)$ of the seropositive group had antibody titre of $\geqslant 1: 8$.

Table 3 Immunity status to rubella among schoolgirls and university female students

\begin{tabular}{lccc}
\hline Age (years) & Seronegative & Seropositive & Total \\
\hline $6-12$ & $89(24 \cdot 4)$ & $276(75 \cdot 6)$ & 365 \\
$13-15$ & $21(8 \cdot 5)$ & $225(91 \cdot 5)$ & 246 \\
$16-18$ & $35(11 \cdot 0)$ & $284(89 \cdot 0)$ & 319 \\
19 & $2(6 \cdot 3)$ & $30(93 \cdot 7)$ & 32 \\
Totals & $147(15 \cdot 3)$ & $815(84 \cdot 7)$ & $926(100 \cdot 0)$ \\
\hline
\end{tabular}

Table 4 Immunity status to rubella among the antenatal group

\begin{tabular}{llll}
\hline Age (years) & $\begin{array}{l}\text { Seronegative } \\
\text { No (\%) }\end{array}$ & $\begin{array}{l}\text { Seropositive } \\
\text { No (\%) }\end{array}$ & Total \\
\hline $15-40$ & $38(5 \cdot 6)$ & $637(94 \cdot 4)$ & 675 \\
\hline
\end{tabular}

\section{Discussion}

Rubella haemagglutination-inhibition test was used until recently for screening by many centres, but this test is said to be inherently unreliable for screening since low concentrations of antibody cannot easily be distinguished from non-specific inhibitors. Therefore, many laboratories are now using more sensitive tests such as single radial haemolysis. ${ }^{49}$ For many years different laboratories have adopted an arbitrary antibody titre as indicative of susceptibilty-for instance, those with titres $1: 16$ are considered as immune, those with $1: 8$ as susceptible. Whether to consider those with a titre of $1: 8$ as seroimmune still remains a controversial issue, 
though many centres including our's do offer the vaccine to this group. Recent work using estimation of $\operatorname{lgM}$ reaction, however, has shown that these patients do not show IgM reaction and thus do not develop viraemia and are thus less likely to cause fetal infection. ${ }^{10}$ In addition to these new methods, many centres have introduced the international unitage system in which sera with a titre greater than $15 \mathrm{IU} \mathrm{ml}$ are considered as immune and those with less than $15 \mathrm{IU} \mathrm{ml}$ as susceptible. Though we do realise the importance, accuracy, and usefulness of these new methods and techniques, until they become available to us we have decided to use our present facilities to get some idea on the epidemiology of rubella in Saudi Arabia.

This study shows that in the absence of a vaccination programme about $90-95 \%$ of girls become seroimmune by marriageable age. Nevertheless, an immunity gap of $5-10 \%$ still exists. This is a relatively lower figure than the figures reported by the WHO collaborative study groups ${ }^{11} 12$ before implementation of rubella vaccination in 1969 , when the immunity gap was found to be $15-20 \%$. It is, however, comparable to figures reported from Kuwait ${ }^{13}$ and Egypt. ${ }^{14}$

In Saudi Arabia cases of congenital rubella are not infrequently observed. In 1981 four cases of definite rubella syndrome were admitted to Riyadh Maternity and Children's Hospital. ${ }^{3}$ The actual figure could even be much higher as most cases are not immediately apparent, missed if mild, or present elsewhere.

As the rubella syndrome is untreatable, therefore, protection of all women of child bearing age is universally regarded as imperative. Furthermore, vaccination is cheaper than providing facilities for handicapped children. It has to be remembered that in some countries, particularly the underdeveloped, these facilities do not even exist.

Immediately in 1969, when the live vaccines were first available, two different strategies were adopted by the Americans and the Europeans including the British. $^{16-18}$

Nevertheless, different publications from the United States reported that a considerable number of women, vaccinated when young, were not protected at child bearing age, and provision of vaccination or a booster to the young or adult female population has been recommended..$^{15}$ The British programme has so far failed to protect all women of child bearing age, and the overall incidence of congenital rubella has not changed. ${ }^{420}$ This was partially attributed to low compliance and high truancy among girls. ${ }^{5}$ For these reasons there was a late recommendation to reinforce the system of vaccination and to organise specific campaigns to encourage rubella vaccination..$^{51}$
In the United States the objective of early vaccination was to eradicate rubella by stopping the circulation of the virus. Even protection rates as high as $86 \%$ will not interrupt transmission, figures of more than $90 \%$ are needed for that. ${ }^{52}$ The general vaccination coverage is low in Saudi Arabia: figures as low as $8-11 \%$ have been reported from rural Saudi Arabia. ${ }^{24-26}$ Even in Riyadh city the highest figure given for poliomyelitis vaccination coverage is around $50 \%,{ }^{28}$ even though it has been mandatory for issuing birth certificates. This was explained by lack of public awareness and administrative shortcomings. Our study has shown that almost all children aged between 24 and 60 months were already seroimmune in the absence of a vaccination programme. For these reasons we do not think that mass vaccination at an early age in Saudi Arabia can be expected to improve the present immune status of children. This is in agreement with the advice against unnecessary mass vaccination of children that has been recommended by other workers from the Gulf area. ${ }^{13}$

We have, however, earlier pointed out thes existence of the $5-10 \%$ immunity gap among the women of child bearing age in Saudi Arabia and too the importance of filling this gap. In the light of these study findings and cultural background we therefore $\vec{D}$ recommend the following vaccination policy for $\infty$ Saudi Arabia.

(1) Rubella vaccine should be given to all fina year elementary schoolgirls (age 10-13) irrespective of their history of rubella or rubella vaccination. The unreliability of the history was shown in this study to accord with experiences elswhere. ${ }^{16}$ Elementary schoolgirls are chosen as a target since they proved to be the oldest susceptible group. Moreover, many drop out from the education system at the end of this level, and fewer girls find a place in junior secondary schools. Those who join the junior secondary school should be asked to submit a rubella vaccination certificate as they do for DPT and poliomyelitis when starting elementary education.

(2) Rubella vaccine should be available in all health centres for those who do not join schools. This is a large group in Saudi Arabia as regular female eduction was introduced late and only $50 \%$ of girls were expected to be enrolled in elementay school in $1980 .^{28}$

(3) To make sure that all girls are vaccinated before marriage, a vaccination certificate should be submitted by the parents before getting the marriage certificate. This policy would need a lot of support from religious leaders, the Mazoons and Imams, who conduct the marriage ceremony and issue the certificates. 
(4) For those who are already married, serological screening for rubella should continue in antenatal clinics where this facility exists. Most health centres and district hospitals, however, have no such facilities. In such places the vaccine should be given to unvaccinated women in the three months postpartum.

Lastly, we think that further nationwide seroepidemiological surveys are still needed to support our findings or else to recommend different policies if their results proved otherwise.

\section{Conclusion}

Our study has shown that $90-95 \%$ of women of child bearing age in central Saudi Arabia are seroimmune. All children between 2 and 5 years gain natural immunity, and we thus do not agree with unnecessary mass vaccination of this group. Nevertheless, the existence of an immunity gap of 5-10\% and presence of cases of congenital rubella syndrome necessitate rubella vaccination. The vaccine should be given to all elementary schoolgirls and non-immunised women at antenatal clinics. Submission of vaccination certificates at various levels and points in life would help to strengthen the programme. To make this policy successful, it should be backed by an intensive health education programme and support from different members of the community, including the religious leaders.

We are grateful to Riyadh Health and Educational Authorities for their help, to the College Medical Research Council for financial grant, to Mrs Fadia Abdu Al Roos for technical help, and to King Abdel Aziz Hospital director for help. We also thank our residents who helped us and $\mathrm{Mr}$ Mohammed Iqbal Qureshi for secretarial help.

\section{Reference}

${ }^{1}$ Gregg NM. Congenital cataract following German measles. Transactions of the Ophthalmological Society of Australia 1984; 3: 35-46.

${ }^{2}$ Modlin JF, Herman K, Brandling-Bennett AD, Eddins LE, Hayden GF. Risk of congenital abnormality after inadvertant rubella vaccination of pregnant women. $N$ Engl J Med 1976; 294: 972-4.

${ }^{3}$ Riyadh Maternity and Children's Hospital Medical Records (1981-1982). Riyadh, Saudi Arabia.

Banatvala JE. Rubella vaccination; remaining problems. Br Med J 1982; 284: 1285-6.

${ }^{5}$ Brooke GDC. Immunisation policies. $\mathrm{Br}$ Med J 1983; 287: 286

${ }^{6}$ Basalamah AH, Serebour FE. Rubella haemagglutination antibodies in females of child bearing age in western region of Saudi Arabia. Saudi Medical Journal 1982; 3: 279-83.

${ }^{7}$ Department of Health Education and Welfare Public Health Service. Serodiagnosis of toxoplasmosis, rubella, cytomegalovirus inclusion disease and herpes simplex. Atlanta, Georgia: Communicable Disease Center Bureau Laboratories, 1977.

${ }^{8}$ Inouye S. Micromodification of kaolin treatment of serum for rubella haemagglutination-inhibition test. Medical Microbiology 1976; 9: 501-2.

${ }^{9}$ Best JM, Harcourt GC, Druce A, Palmer SL, O'Shea S, Banatvala JE. Rubella immunity by four different techniques: results of challenge studies. J Med Virol 1980; 5: 239-47.

${ }^{10}$ Mortimer PP, Edwards JMB, Porter AD, Tedder RS, Mace JE, Hutchinson A. Are many women immunized against rubella unnecessarily? J Hyg 1981; 87: 131-8.

${ }^{11}$ Cockburn WC. World aspects of the epidemiology of rubella. Am J Dis Child 1969; 118: 112-22.

${ }^{12}$ Rawls WE, Melnick JL, Bradstreet CMP, et al. WHO collaborative study group on seroepidemiology of rubella. Bull WHO 1977; 37: 79-88.

${ }^{13}$ Hathout H, Al Nakib W, Hazzel Lilley H, Shalaby AA, Nosseir AF. Seroepidemiology of rubella in Kuwait: an alternative vaccination policy. Int J Epidemiol 1978; 7: 47-53.

${ }^{14}$ Khalifa A, Samy Kouka SE, Abel W, Imam IZE. Seroimmunity to rubella among an Egyptian population. $J$ Infect Dis 1973; 127: 567- 70.

${ }^{15}$ Hinman AR, Preblud SR, Brandling-Bennett AD. Rubella; the US experience. International symposium on immunization: benefit versus risk factors. Brussels, 1978. Developmental and Biological Standards 1979: 43: 315-26.

${ }^{16}$ Dudgeon JA, Marshall WC, Peckham CS. Rubella vaccine trials in adults and children. Am J Dis Child 1969; 118: 237-42.

${ }^{17}$ Dudgeon JA. Proposed vaccination in Europe: III Rubella in the application of vaccine against viral rickettsial and bacterial diseases of man. WHO SC.00 $1970 \quad 14-18$ December, Washington. Washington: World Health Organisation, 1970.

${ }^{18}$ Mande R, Vaccination contre la rubeolde. Ann Paediat 1970; 17: 783-9.

${ }^{19}$ Krugman S. Rubella immunization: progress, problems and potential solutions. American Journal of Public Health 1979; 69: 217-8.

${ }^{20}$ Vaile MSB. Factors influencing rubella immunity in women. $\mathrm{Br}$ Med J 1982; 282: 738.

${ }^{21}$ Dudgeon JA. Rubella: the UK experience. International symposium on immunization: benefit versus risk factors. Brussels, 1978. Developmental and Biological Standards $1979 ; 43 ; 327-38$.

${ }^{22}$ Krugman S. Rubella immunization: present status and future prospective. Pediatrics 1980; 65: 1174-6.

${ }^{23}$ Michael RL, Abramson JS, Joseph EH, Doris SK. Rubella susceptibility in six graders. Effectiveness of current immunization practice. Pediatrics 1980; 65: 1086-9.

${ }^{24}$ Abdullah MA, Sebaie ZA. Health and nutritional status of preschool children. In: Sebaie ZA, ed. Community health in Saudi Arabia. Saudi Medical Journal Monographs 1982; 1: 11-8.

${ }^{25}$ Sebaie ZA, Serrenious F, Hazmi M. Health profile of preschool children in Tamnia villages, Saudi Arabia. Saudi Medical Journal 1981; 2, suppl: 68-71.

${ }^{28}$ Sebaie ZA. The health of the family in a changing Arabia. Saudi Arabia: Tuhama Publications, 1981: 117-28.

${ }^{27}$ Nofal HS. Paralytic poliomyelitis in Saudi Arabia; a retrospective study on incidence and control. In: Proceedings of symposium on immunization against childhood diseases, Riyadh 1981. Belgium: Smith Kline, 1981: 59-69.

${ }^{28}$ Dudgeon JA. Measles and rubella vaccines. Arch Dis Child 1975; 52: 907-11. 